\title{
Interactive comment on "Radiative properties of mid-latitude cirrus clouds derived by automatic evaluation of lidar measurements" by Erika Kienast-Sjögren et al.
}

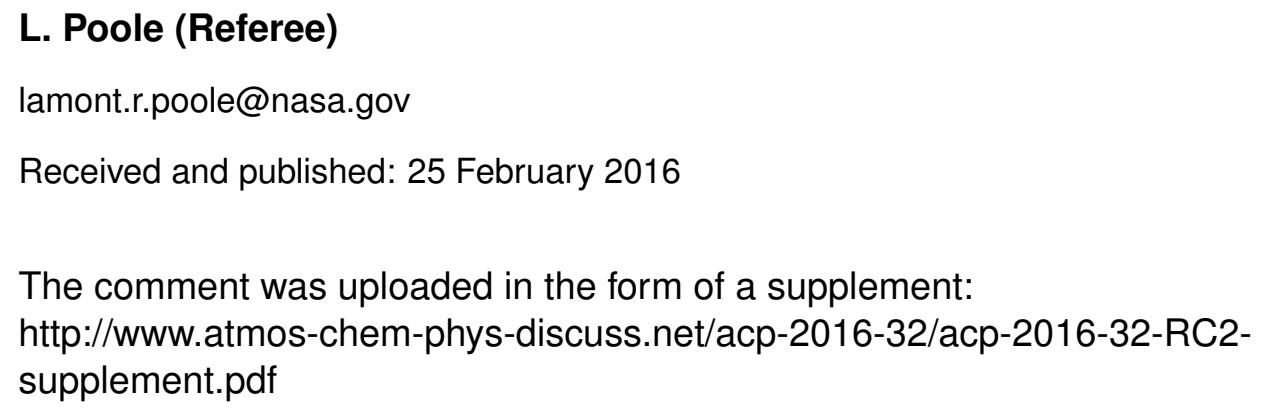

